\title{
Rank positions in rats and their relations to tissue parameters
}

\author{
K. MILITZER \\ Central Animal Laboratory for Experimental Medicine, University Clinic \\ Essen, Federal Republic of Germany \\ and \\ H.-J. REINHARD \\ Institute of Statistics and Biometry, Faculty of Veterinary Medicine \\ Hannover, Federal Republic of Germany
}

\begin{abstract}
Spontaneous behavioral categories such as attack, submission, boxing, allogrooming, mounting, and anogenital control were investigated in nine groups of three rats each. At the same time, the number of wins in the runway test and the amount of time spent occupying access-to-water space were registered in competitive tests. Antagonistic behavior (attack and induction of submission) permitted no significant relationships to be drawn as to the results of the competitive tests. The competitive parameters, too, showed no correlation among themselves. In agreement with other authors, we reject the existence of an encompassing unidimensional rank order in rats on the basis of these results. Attack wins and induction of submission showed a positive correlation to one another as well as to relative thymus and testes weights. A high antagonistic activity was also correlated with low relative adrenal weight, large number of nuclei in the adrenal cortex, and wide tubuli seminiferi in the testes. As indicated by factor analysis, a significant decrease in body weight, low heart, thymus, liver, spleen, kidney, and testes weights, and high adrenal weight with decreased number of nuclei in the adrenal cortex were typical for rats with low aggressive rank positions. The influence of endocrine organs and diminished physical vitality in these low-ranking animals was also observed following nonsocial stress.
\end{abstract}

Through the breeding of laboratory rats, intraspecies aggressiveness can, to a large extent, be reduced. Therefore, unlike with the chickens used by Schjelderup-Ebbe (1922), it is almost impossible to establish the social rank of a rat exclusively from the outcome of an attack. Thus, in order to determine rank position among rats, additional behavioral parameters, such as those resulting from competitive situations, after restriction of food and water, location, sexual partner, or avoidance of such unpleasant experiences as electroshock and oxygen deficiency (Kreveld, 1970) were drawn upon (Table 1).

This gives the impression that the hierarchical organization within rat collectives is easily determined by means of simple experimental procedures. It was thus assumed that the experimentally established rank position of a single parameter definitely deter-

The authors thank Peter Tamulevicius, Institute of Radiobiology, University Clinic, Essen, for criticism and translation of this manuscript. The first author's mailing address is: Zentrales Tierlaboratorium für Experimentelle Medizin am Universitătsklinikum, Hufelandstr. 55, D-43 Essen 1, Federal Republic of Germany.

-Article accepted by previous editor, Richard F. Thompson mined the dominance of an animal within the group (criticized as concept of "unidimensionality of dominance" by Syme, 1974).

Various publications, however, have indicated that no uniform order of dominance can be detected (Table 1) if several test procedures are used in parallel.

The value of such reports on dominance rank, dominance hierarchy, or social hierarchy (Wilson, 1975 ) in rats, however, is often limited, since methodological shortcomings in the investigations are apparent: (1) As a rule, maximally two independent methods are chosen for rank determination and their relevance tested statistically (Table 1 ). The overall interpretation will thereby be significantly restricted. (2) The rats will be subjected to the competitive test procedures either pairwise or on a round-robin system. Therefore, they cannot form real social groups, so that the correlations found between them possess little relevance (Chase, 1974; Timmermans, 1978). (3) The various rank tests are not conducted in parallel at the same time but often in series at extended time intervals. The rank order may have changed during the course of the experiment (Timmermans, 1978). (4) The training achievements, which influence the outcome of the subsequent competitive rank 
Table 1

Review of the Literature for Testing Rank Positions in Rats With More Than One Experimental Procedure

\begin{tabular}{|c|c|c|c|c|c|c|c|c|c|c|c|c|c|c|c|c|c|c|c|c|c|}
\hline \multirow[b]{3}{*}{ References } & \multirow{2}{*}{\multicolumn{8}{|c|}{$\begin{array}{c}\text { I } \\
\text { Spontaneous } \\
\text { Behavior }\end{array}$}} & \multirow{2}{*}{\multicolumn{5}{|c|}{$\begin{array}{c}\text { III } \\
\text { Tissue } \\
\text { Param- } \\
\text { eters } \\
\end{array}$}} & \multirow[b]{3}{*}{ IV* } & \multirow[b]{3}{*}{ Q } & \multicolumn{6}{|c|}{ Significant Relations } \\
\hline & & & & & & & & & & & & & & & & \multicolumn{3}{|c|}{$\begin{array}{c}\text { Between } \\
\text { Tests I-IV }\end{array}$} & \multicolumn{3}{|c|}{$\begin{array}{c}\text { Within } \\
\text { Tests I-IV }\end{array}$} \\
\hline & a & b & d & f & $\mathrm{m}$ & 0 & $\mathbf{s}$ & $\mathrm{z}$ & F & W & $\mathbf{R}$ & BW & o* & & & $\mathrm{Y}$ & $\mathrm{N}$ & B & Y & $\mathbf{N}$ & B \\
\hline Bruce, 1941 & & & & & & & & & $\mathbf{x}$ & $\mathbf{x}$ & & & & & & & & & & & \\
\hline Barnett, 1958 & & & & $\mathrm{x}$ & & & & & & & & $\mathbf{x}$ & 1,2 & & & & $\mathrm{x}$ & & & $\mathrm{x}$ & \\
\hline Grant \& Chance, 1958 & & & & $\mathbf{x}$ & $\mathrm{x}$ & & & & & & & & & & & & & & $\mathrm{x}$ & & \\
\hline Mezei \& Rosen, 1960 & & & & & & & & & $\mathrm{x}$ & & & $\mathbf{x}$ & & & & & & & & & \\
\hline Candland \& Bloomquist, 1965 & & & & & & & & & $\mathrm{x}$ & & & $\mathbf{x}$ & & & & $\mathrm{x}$ & & & & & \\
\hline Baenninger, 1966 & & & & $\mathrm{x}$ & & & $\mathrm{x}$ & & & & & $\mathbf{x}$ & & & & $\mathbf{x}$ & & & & & \\
\hline Schumsky \& Jones, 1966 & & & & & & & & & & & $\mathbf{X}$ & $\mathbf{x}$ & & & $\mathbf{x}$ & $\mathrm{x}$ & & & & & \\
\hline Lester, 1967 & & & & & & & $\mathrm{x}$ & & & & & $\mathbf{x}$ & & 5 & & & & $\mathrm{x}$ & & & \\
\hline Ward \& Gerall, 1968 & & & & & & & & & & & $\mathbf{x}$ & $\mathbf{x}$ & & & & $\mathrm{x}$ & & & & & \\
\hline Hoyenga \& Rowe, 1969 & & & & & & & & & $\mathrm{x}$ & $\mathrm{x}$ & & & & & & & $\mathrm{x}$ & & & & \\
\hline Oldfield-Box, 1969 & & & & & & & & & $\mathbf{x}$ & & & & & 6 & & & $\mathbf{x}$ & & & & \\
\hline Work et al., 1969 & & & & & & & & & & & $\mathrm{x}$ & $\mathbf{x}$ & & & & & $\mathbf{x}$ & & & & \\
\hline Baenninger, 1970 & & & & & & & $\mathrm{x}$ & & $\mathrm{x}$ & $\mathbf{x}$ & & $\mathbf{x}$ & & & & & $\mathbf{x}$ & & $\mathrm{x}$ & & \\
\hline Hoyenga \& Lekan, 1970 & & & & & & & & & $\mathbf{x}$ & & & $\mathbf{x}$ & & & & $\mathrm{x}$ & & & & & \\
\hline Monroe, 1970 & & & & & & & & & & & $\mathbf{x}$ & $\mathbf{x}$ & & & & & $\mathbf{x}$ & & & & \\
\hline Ruskin \& Corman, 1971a, 1971b & & $\mathbf{x}$ & & $\mathbf{x}$ & & & & & $\mathbf{x}$ & & & & & 7 & & $\mathrm{x}$ & & & $\mathrm{x}$ & & \\
\hline Boreman \& Price, 1972 & & & & & & & $\mathrm{x}$ & & & $\mathbf{x}$ & & $\mathbf{x}$ & & & & $\mathbf{x}$ & & & & & \\
\hline Spigel et al., 1972 & $\mathrm{x}$ & & & & & & & & & $\mathrm{x}$ & & & & & $\mathbf{x}$ & $\mathrm{x}$ & & & & & \\
\hline Popova \& Naumenko, 1972 & & & & $\mathbf{x}$ & & & $\mathbf{x}$ & & & & & & 3 & & & $\mathbf{x}$ & & & & & \\
\hline Howells \& Kise, 1974 & & & $\mathbf{x}$ & & & & & & $\mathbf{x}$ & & $\mathbf{x}$ & & & 5 & & & $\mathrm{x}$ & & & $\mathrm{x}$ & \\
\hline Syme et al., 1974 & & & & & & & & & $\mathbf{x}$ & $\mathbf{x}$ & & $\mathbf{x}$ & & & $\mathbf{x}$ & & $\mathbf{x}$ & & & $\mathbf{x}$ & \\
\hline Drews \& Wulczyn, 1975 & $\mathbf{x}$ & $\mathbf{x}$ & & $\mathrm{x}$ & $\mathrm{x}$ & & $\mathbf{x}$ & $\mathbf{x}$ & $\mathrm{x}$ & & & $\mathbf{x}$ & & & & & & $\mathbf{x}$ & $\mathbf{x}$ & & \\
\hline Fukasawa et al., 1975 & & & $\mathbf{x}$ & & & & & & $\mathbf{x}$ & & $\mathbf{x}$ & & & & & & $\mathrm{x}$ & & & $\mathrm{x}$ & \\
\hline Miczek \& Barry, 1975 & & & & $\mathrm{x}$ & & & & & & & $\mathbf{x}$ & & & & & & $\mathrm{x}$ & & & & \\
\hline Taylor \& Moore, 1975 & & & & $\mathbf{x}$ & & & & & $\mathbf{x}$ & $\mathbf{x}$ & & & & & & & & & & & \\
\hline Price \& Huck, 1976 & $\mathrm{x}$ & & $\mathbf{x}$ & & & $\mathbf{x}$ & & & & & $\mathbf{x}$ & & & 7,8 & & & $\mathbf{x}$ & & $\mathbf{x}$ & & \\
\hline Costanzo et al., 1977 & & & & & & & & & $\mathbf{x}$ & & & & & 9 & & & $\mathbf{x}$ & & & & \\
\hline Drews \& Dickey, 1977 & $\mathrm{x}$ & $\mathbf{x}$ & & $\mathbf{x}$ & $\mathbf{x}$ & & $\mathbf{x}$ & $\mathbf{x}$ & $\mathbf{x}$ & $\mathbf{x}$ & & & & & & $\mathbf{x}$ & & & & & $\mathbf{x}$ \\
\hline Gage, 1978 & $\mathbf{x}$ & $\mathbf{x}$ & & $\mathbf{x}$ & & $\mathbf{x}$ & & & $\mathbf{x}$ & & & & & 7 & & & & & $\mathbf{x}$ & & \\
\hline Davis, 1979 & & & & $\mathbf{x}$ & & & & & & & & $\mathbf{x}$ & 1 & 10 & & $\mathbf{x}$ & & & & $\mathrm{x}$ & \\
\hline Gärtner et al., 1981 & & & & & & & & & & $\mathrm{x}$ & & & & 11,12 & & & $\mathbf{x}$ & & $\mathrm{x}$ & & \\
\hline Present Experiment & $\mathbf{x}$ & $\mathbf{x}$ & & $\mathbf{x}$ & $\mathbf{x}$ & $\mathrm{x}$ & $\mathbf{x}$ & $\mathbf{x}$ & & $\mathbf{x}$ & $\mathbf{x}$ & $\mathbf{x}$ & 4 & & & & $\mathbf{x}$ & & $\mathbf{x}$ & & \\
\hline
\end{tabular}

Note-The training conditions and the results of correlation analyses were especially considered. $Q=$ quantifying the training success from II; $Y=$ yes, $N=$ no, $B=$ both; $x=$ applies. Parameter symbols: $a=$ allogrooming, $b=$ boxing, $d=$ defecation, $f=$ fighting, $m=$ mounting, $o=$ other parameters, $s=$ submission, $z=$ sum of overall activities, $B W=$ body weight, $F=$ food competition, $R=$ runway test, $W=$ water competition. $\quad *$ Other parameters: $1=$ adrenals, $2=$ thyroids, $3=$ plasma corticosterone level, $4=11$ tissue paraineters, $5=y$-maze, $6=$ leverpressing, $7=$ locomotion, $8=$ wall seeking, $9=$ emotionality, $10=$ bite wounds, $11=$ copulation, $12=$ fathering.

test, are only rarely quantified and drawn into the evaluation of the overall experiment (Syme, 1974; Table 1).

The aim of the following experiment was to determine whether different rank test methods-two independent competitive tests and the registration of antagonistic and contact behavioral activities in ratslead to identical results. Particular emphasis was placed on adherence to the above-mentioned points.

The initial question to be answered was whether simultaneously applied behavioral and competitive parameters were effective in the determination of dominance. Their significance for the rank positions of rats was not to be assessed for the individual but for the overall experimental data instead. Subsequently, it was attempted to quantify and to analyze statistically more than 12 tissue parameters of the animals in relation to the rank determining parameters.

The influence of the rat's physical constitution on rank positions was to be assessed more closely. Up to now only a few morphological data, apart from body weight, have been evaluated with respect to experimentally determined dominance ranks (Table 1 ).

\section{METHODS}

\section{Animals}

Twenty-seven male albino rats (nine each of Lewis, SpragueDawley, and Wistar strains, bred at Central Institute for Laboratory Animals, Hannover), 48 to 52 days old on arrival, were used (Figure 1).

Prior to the dominance tests, the animals were kept singly under 


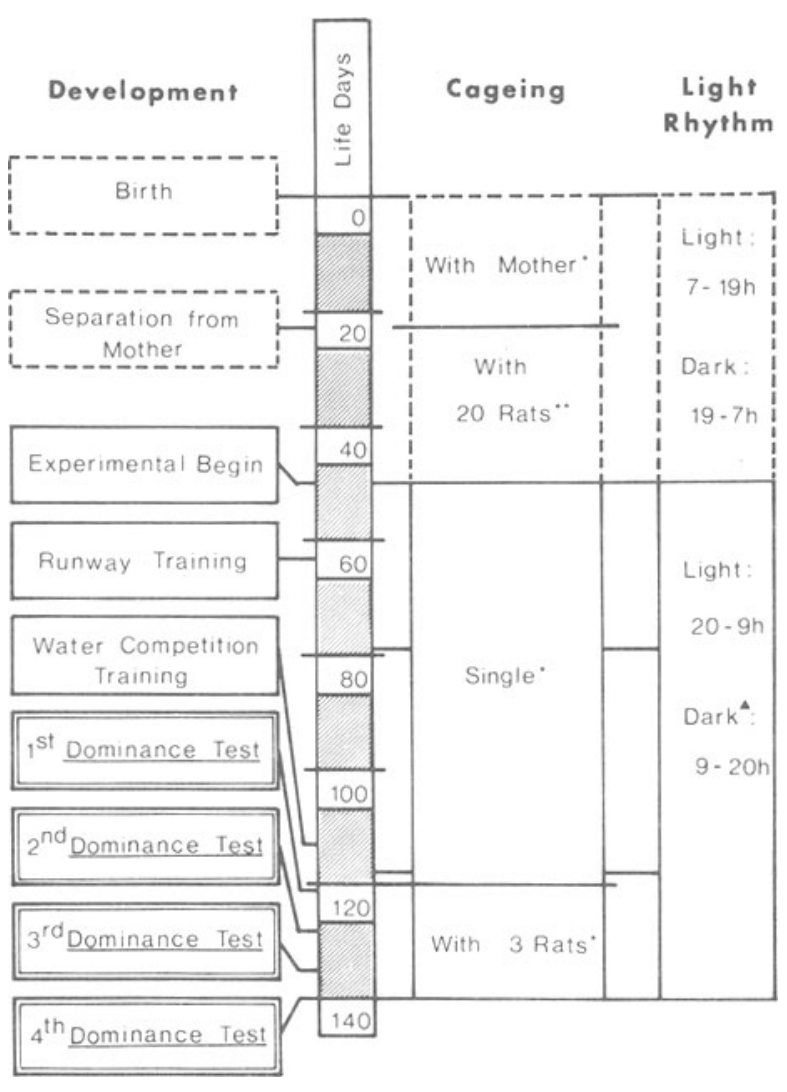

Figure 1. Details of age development of the experimental animals and conditions of maintenance. Dashed lines: Period of maintenance at the breeder without experimenter control. *Cage sizes: $29 \times 23 \times 15 \mathrm{~cm}$. **Cage sizes: $55 \times 33 \times 20 \mathrm{~cm}$. $\triangle$ Red light.

standard conditions (room temperature, $21^{\circ} \pm 2^{\circ} \mathrm{C}$; R.H., $50 \%$ $\pm 5 \%$; feed, Altromin-Lage/Lippe, Type R-1324) and water ad lib in polycarbonate (Macrolon) cages $(29 \times 23 \times 15 \mathrm{~cm})$. The rats were maintained under a reversed light cycle for the total period of the experiment (artificial light, 1900-0800 h; 40-W dimmed red light during the daytime).

\section{Training Procedure}

Water and runway test training and the actual experiments were carried out during the red-light phase $(0800-1300 \mathrm{~h})$. Runway training was initiated 13 days after arrival of the rats.

Each of the rats, starved for $22 \mathrm{~h}$, was allowed to acquaint itself with the runway, whose gates were open, in the first 3 days for $4 \mathrm{~min}$ per day. The rats were then trained by being allowed to hurry into the alley after the startbox gate was opened and then to wait for $3 \mathrm{sec}$ at the central gate. After the central gate was opened, they ran into the goalbox opposite, where they were rewarded with a food pellet. The time taken for crossing the runway during training was measured and then summed up for the overall training phase and given as runway training time in seconds in the statistical analysis of all data.

Fifty-one days after training had begun, the conditioning of the rats to the polycarbonate water competition test box $(33 \times 55 \times$ $20 \mathrm{~cm}$ ) was initiated. Over 6 days, the animals, which had received no drinking water for $20 \mathrm{~h}$, were placed separately into the test box. Through a $3.2-\mathrm{cm}$-diam hole in the small side of the box, they were able to drink for a maximum of 2 min from an externally positioned bottle. The time taken for the rat to find the water after placement was recorded. The times registered in the 6 days of training were summed up and included as water-finding training time in seconds in the analysis of test results.
At the end of the training time, at 120 days of age, the rats were individually marked by coloring of the hair and the strains randomly divided into groups of three. These groups remained unchanged throughout the experiment. The first rank test was carried out on the following day.

\section{Rank Test Design}

For each group of rats on the same day, the following tests were carried out four times at intervals of 1 week (Figure 1):

(1) Observation of social behavior. During the first $10 \mathrm{~min}$ of the red-light phase, the behavior of the three rats in each group was observed and tape-recorded, always by the same observer. The frequency of the following behavior categories was included for each animal:

Wins during attack behavior-The rats rolled over one another so quickly that details were not discernible. Biting and raised screeching noises were established. The rat that neither fled nor submitted was evaluated as winner.

Wins during boxing and offensive upright-The animals raised themselves on their hindlegs and battered each other with their forelegs. The winner was the rat that raised up higher than, and turned its head toward, its opponent.

Induction of submission-The submissive animal assumed a motionless position on its side, while the winner placed his front paws or head on its ventral surface.

Activity of allogrooming-The active rat bit or licked the fur of another.

Frequency of mounting and walking over-The animal embraced the passive rat dorsally or ran over it.

Activity of sniffing and anogenital licking-The animals controlled each other by sniffing the flank, belly, and anogenital region.

Total activity-The frequency of the above-listed behavioral categories and the passive behavior of the loser in each case was summarized.

(2) Runway test. Animals were paired with one another in each group of three in a predetermined randomly order. Simultaneously, from both start boxes, two of the three rats that had been starved for $27 \mathrm{~h}$ were released into the runway. The animals met at the central gate and attempted to push each other out of the alley. The rat that pushed the defeated animal back into its startbox was the winner. With a single repetition $1.5 \mathrm{~h}$ after the first test, 6 runs per group and experimental day were conducted. The number of wins per rat was statistically evaluated.

(3) Water-competition test. The three thirsty animals $(28.5 \mathrm{~h}$ water deprived) from each group were brought into the drinking test box for $5 \mathrm{~min}$. Only one rat could reach the water bottle at any one time. The drinking time per rat and test was recorded by hand by two observers. The test was repeated after $1.5 \mathrm{~h}$. The natural logarithm of drinking time per rat was evaluated.

\section{Morphometry}

At the end of the last rank test (Figure 1), the rats were sacrificed with ether. Heart, thymus, liver, spleen, kidneys, adrenals, and testes were carefully dissected, weighed, and fixed in 3\% formaldehyde. Approximately 5- $\mu$ m-thick sections were stained with hematoxylin-eosin and according to Masson-Goldner. The number of nuclei in the adrenal cortex per unit area for each rat was determined from parenchymal nuclei of the zona glomerulosa at a $1,000 \times$ magnification by counting 50 squares $(48 \times 48 \mu \mathrm{m})$. The thickness of the cortex was measured at a $63 \times$ magnification at four diametrically opposite points per slice, that is, a total of eight measurements per rat. The size of the medulla was estimated from the two largest diameters at right angles to each other. Twenty diameters from roughly round tubuli seminiferi, including the tunica propria, per testis were measured at a $160 \times$ magnification.

\section{Data Analysis}

The biostatistical analysis of the results was conducted in two stages. Initially, the absolute frequencies of behavioral categories and determinations of competition training and tests were evaluated 
for the individual parameters irrespective of group. This was done by correlating (Spearman's $r$ ) all of these observed data from the overall experiment.

In this way, the number of data for certain behavioral categories increased significantly in comparison with those from individual test days. Highly positive correlations between antagonistic behavioral and competitive parameters would mainly suggest a unidimensional order of dominance in rats. This was, however, not to be expected from the literature (Table 1). Significant positive correlations should exist between training and test competition results, if the parameters chosen by us as measures of training success (which were not identical to rank test criteria) were to be decisive for the results.

In the next stage only the parameters of the last test day were evaluated statistically in order to achieve clear and definite correlations.

Apart from the absolute number of wins in runway test and water-drinking time during competition, the frequency of antagonistic behavior, that is, the sum of attack and submission frequencies per animal, was investigated as the aggressive dominance index (ADI). For the rank index, the sum of the relative rank positions per animal for the above mentioned three behavioral measures was combined. The rat from each group with the highest success in rivalry was designated number 3 , and the least successful, number 1 . From these rank data and the results of quantitative morphometrical investigations, multiple correlation analyses were carried out. This statistical method, however, only allows deductions to be made about the probable relations between two parameters, without attaching any great importance to their dependence on one another.

In accordance with Aspey and Blankenship (1977), a principalcomponent factor analysis with rotation of factors by the Varimax procedure was therefore included. This type of analysis not only considers the dependence of the parameters to one another and reduces the number of variables in the test series, but also reveals possible cause-related groups of parameters in the form of "factors" (Balthazart, 1972). The statistical results therefore support not only the hypotheses confirmed, as is the case for most procedures, but also allow a new formation for them to be made.

\section{RESULTS}

\section{Behavior and Competition}

From the data of the total experiment shown in Table 2, it can be seen that behavioral categories (Nos. 3-9) and parameters of training and testing for competition (Nos. 10-13) bear only a few significant relations to each other. In contrast, several variously oriented correlations exist between the behavioral categories. Thus, the number of attack wins correlates positively with the induction of submission and total activity (Table 2, Nos. 3 to 5, 9). At the start of the experiment, aggressive rats possess, on average, a higher body weight than do nonaggressive rats (Nos. 1 to 3). They rarely carry out allogrooming on their cage partners (Nos. 3 to 6).

Boxing shows no significant relationship to antagonistic behavior. It is the only behavioral category in which positive correlations are seen not only to the length of training time but also to the number of wins in the competitive runway test (Table 2, Nos. 4 to $10,11)$.

Rats that frequently engaged in allogrooming seldom carry out anogenital control as do the aggressive rats, and they have high body weights (Nos. 6 to 8,2 to 6 ). Only short periods of time are required during training for the runway test for them to reach the goal cage from the startbox (Nos. 6 to 10).

Mounting cannot be correlated with any of the behavioral and competitive parameters. Rats which have been induced in manyfold behavioral activities require longer periods during runway training in

Table 2

Significant Overall Correlation Coefficients $(p<.01)$ of Body Weight, Absolute Frequencies of Behavioral Categories, and the Measures of Competition Training and Test

\begin{tabular}{|c|c|c|c|c|c|c|c|c|c|c|c|c|c|}
\hline \multirow{2}{*}{$\begin{array}{l}\text { Param- } \\
\text { eter }\end{array}$} & \multicolumn{13}{|c|}{ Parameter } \\
\hline & 1 & 2 & 3 & 4 & 5 & 6 & 7 & 8 & 9 & 10 & 11 & 12 & 13 \\
\hline 1 & & .718 & .577 & & & & & & & & & & \\
\hline 2 & & & & .786 & & .733 & & & & & & & .890 \\
\hline 3 & & & & & .853 & -.782 & & & .662 & & & & \\
\hline 4 & & & & & & -.102 & & -.846 & & .782 & .945 & & \\
\hline 5 & & & & & & & & & .628 & & & & \\
\hline 6 & & & & & & & & -.765 & & -.861 & & & \\
\hline 7 & & & & & & & & & & & & & \\
\hline 8 & & & & & & & & & & & & & \\
\hline 9 & & & & & & & & & & .860 & & & \\
\hline 10 & & & & & & & & & & & .918 & & \\
\hline 11 & & & & & & & & & & & & -.668 & \\
\hline 12 & & & & & & & & & & & & & \\
\hline 13 & & & & & & & & & & & & & \\
\hline
\end{tabular}

Note-Parameters: $1=$ body weight (in grams) at start of experiment (total $=27), 2=$ body weight (in grams) at end of experiment (total $=27), 3=$ number of at tack wins (total $=404), 4=$ number of boxing wins (total $=91), 5=$ frequency of induction of submission (total $=248$ ), $6=$ frequency of allogrooming activity (total $=60), 7=$ frequency of mounting activity (total $=80), 8=$ frequency of anogenital control (total = 271), $9=$ total activity (total = 2,442), 10 = runway training time (duration of runs, in seconds) $11=$ number of runway wins in tests, $12=$ water finding training (duration, in seconds), $13=$ water competition (drinking time in tests, in seconds). 
order to solve the problem (Table 2, Nos. 9 and 10).

In the runway test, the dominant rats are those which traverse the alley only slowly in training compared to those which are fastest in training (Nos. 10 and 11). The former grasp the next problem-the finding of the water bottle-quickly, as seen from the negative correlation between parameters 11 and 12 in Table 2. Successful water competition test rats possessed high body weights (Nos. 2 to 13), but did not show any significant correlations to behavioral, training, and competition results.

\section{Morphometrical Results and Rank Positions}

The absolute organ weights and histometrical data have already been published (Militzer \& Reinhard, 1979b), so now only the significant correlation coefficients are given in Table 3. This table shows that a high aggressive dominance index (ADI) is correlated only with high relative weights of thymus and testes and with low relative weights of adrenals (Table 3 , Nos. 1 to $10,15,20$ ). Rats which frequently achieve wins in the runway test clearly show gains in body weight and high final weights. The spleen and testes are heavy and the testicular tubuli possess wide lumina (Nos. 2 to 5, 6, 12, 20, 21). Long drinking times during the water competition are correlated with high body weights and with high absolute kidney and adrenal weights during the test (Nos. 3 to 5 , $7,13,14)$.
The negative correlation with the relative weights of the adrenals indicates that no hyperplasia of the adrenals occurs in the drinking-dominant animals, but rather a positive dependence between the absolute body weight and endocrine weight (Table 3, Nos. 3 to 15 ). In these rats, the nuclear count per unit area of adrenal cortex is high, since no functional nuclear and cell edema exist. The thickness of the adrenal medulla is low (Nos. 3 to 17,18 ).

The rank index, as a summary of the three different rank test results, shows a significant, but not independent, relation to drinking time during competition (Nos. 3 and 4). Furthermore, novel already proven correlations are missing in the single tests. The absolute weights of heart, liver, spleen, kidneys, adrenals, and testes allow a positive correlation to be made with the parameters of body development (Table 3, Nos. 5-7). In contrast, the lighter rats possess relatively high adrenal weights (Nos. 7 to 15). The weight of the thymus is negatively correlated with the weights of the spleen and kidneys as well as the nuclear count of the adrenals (Nos. 9 to $12,14,16$ ). The thickness of the adrenal cortex and medulla is positively correlated (Table 3, 16 to 17), whereas the number of nuclei in the cortex is negatively correlated with the thickness of the medulla (Nos. 16 to 18). Heavy testes are associated with wide tubuli seminiferi (Nos. 19 to 21 ); the diameters of the tubuli are negatively correlated with the thickness of the cortex but positively

Table 3

Significant Correlation Coefficients $(p<.01)$ of Rank and Morphological Data of the Last Experimental Day

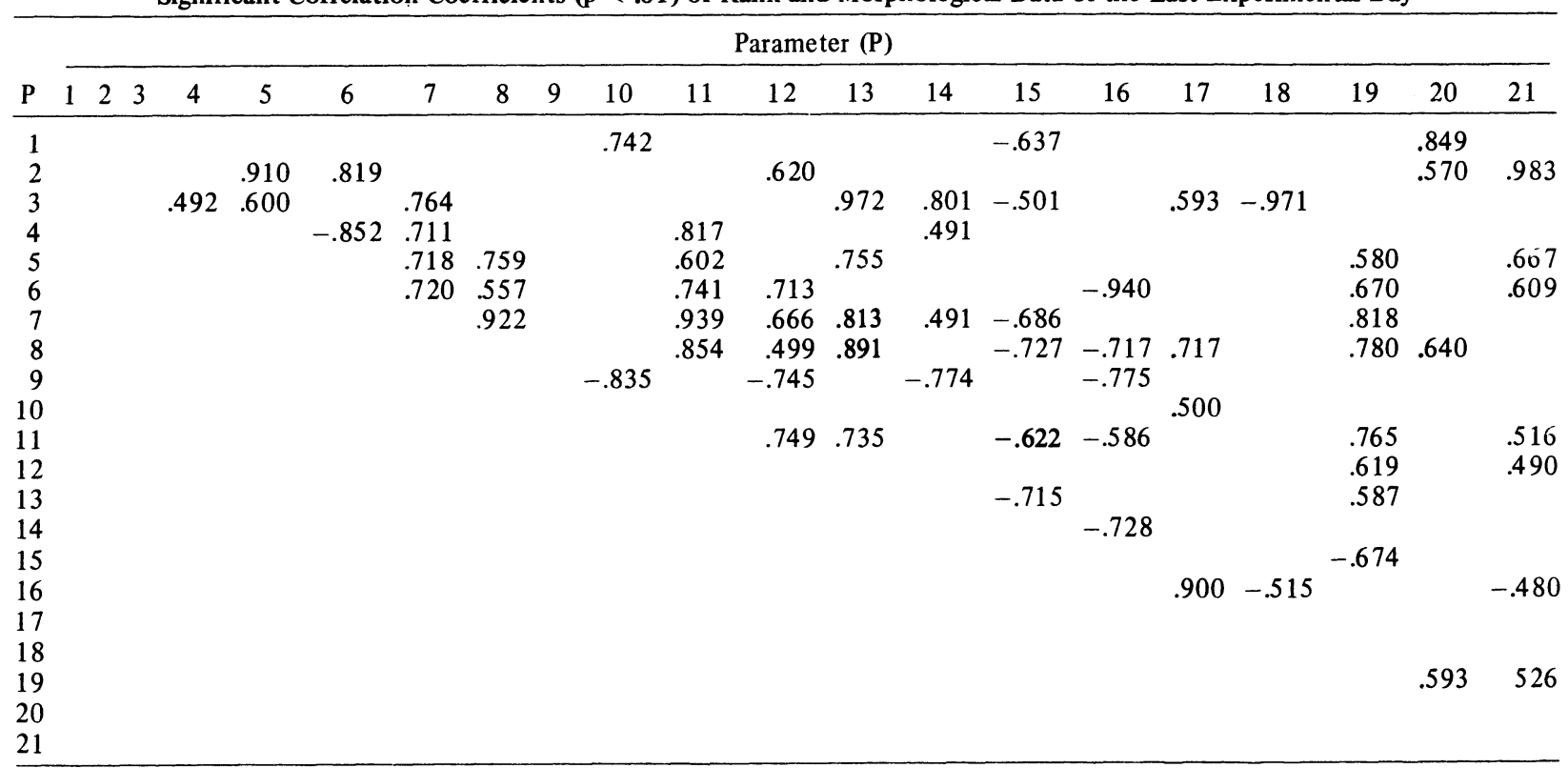

Note-Parameters: $1=$ aggressive dominance index, $2=$ wins in runway test, $3=$ drinking time in water competition, $4=$ rank index (sums of rank positions in Parameters 1-3), $5=$ body weight at start, $6=$ body weight increase during experiment, $7=$ body weight at end, $8=$ heart weight (absolute), $9=$ thymus weight (absolute), $10=$ thymus weight (relative), $11=$ liver weight (absolute), $12=$ spleen weight (absolute), $13=$ kidneys weight (absolute), $14=$ adrenals weight (absolute), $15=$ adrenals weight (relative), $16=$ thickness of adrenal cortex. $17=$ nuclear count in adrenal cortex, $18=$ thickness of adrenal medulla, $19=$ testes weight (absolute), $20=$ testes weight (relative), 21 = diameter of tubuli seminiferi. 
correlated with the weights of the liver and spleen (Nos. 11, 12, 16 to 21).

Since they influence each other in terms of size, many of our test parameters are not independent variables. Since it is especially possible to determine the pattern of relationships among the dependent measures with the aid of factor analysis, these results are presented in detail in Table 4. Eighty-four percent of the total experimental variability can be explained by means of the seven mentioned factors.

Factor 1 contains negatively oriented parameters of the ADI, body weight development, and absolute weights of heart, thymus, liver, spleen, kidneys, and testes. These factors are oppositely further loaded due to the relative weights of the adrenals.

On the whole, parameters of diminished physical vitality and nonsuccess in antagonistic behavioral situations are thus determinable.

Factor II, likewise, is made up from the state of the body and organ weights (liver, spleen, adrenals, testes), although with a positive orientation. Also included is the functional dependence of the fine structure of the adrenals and testes on the nuclear count of the adrenal cortex and diameter of the tubuli seminiferi, respectively. The indirect relationship between the nuclear count and the adrenal weight was established by the correlation analysis. Factor II mainly reflects the influence of body weight gain and development of organ weights on the bodily fitness of rats.

The loading of Factor III from the weights of the adrenals, thickness of adrenal medulla, and weights of the testes, the latter with opposing sign, is to be considered as an expression of the hormonal burden during the rank tests.

Factor IV exclusively contains parameters of rank testing, which are, however, oppositely oriented. Thus, ADI represents antagonistic behavior, whereas the retreat from the alley describes defensive behavior.

Factor $\mathrm{V}$ is loaded in the same way for drinking time in water competition and rank index. The absolute and relative thymus weight is the only morphological parameter to be found in this factor.

Factor VI shows the rank index and the thickness of the adrenal medulla as negative, whereas the thickness of the adrenal cortex is positive. This indicates an increase in the expansion of the adrenal cortex at the expense of the size of the medulla in rats with low competitive rank.

Factor VII, finally, is again loaded through the absolute and relative thymus weight, as in Factor $\mathrm{V}$.

\section{DISCUSSION}

From the literature on dominance testing in rats considered by us, only about one-third of the pub-

Table 4

Results of the Orthogonal Factor Analysis (Varimax) for Parameters of the Last Experimental Day

\begin{tabular}{|c|c|c|c|c|c|c|c|}
\hline Parameter & $\begin{array}{c}\text { Factor I } \\
(\mathrm{EV}=31 \%)\end{array}$ & $\begin{array}{c}\text { Factor II } \\
(\mathrm{EV}=14 \%)\end{array}$ & $\begin{array}{c}\text { Factor III } \\
(\mathrm{EV}=10 \%)\end{array}$ & $\begin{array}{l}\text { Factor IV } \\
(\mathrm{EV}=8 \%)\end{array}$ & $\begin{array}{l}\text { Factor V } \\
(\mathrm{EV}=8 \%)\end{array}$ & $\begin{array}{l}\text { Factor VI } \\
(\mathrm{EV}=7 \%)\end{array}$ & $\begin{array}{r}\text { Factor VIII } \\
(E V=6 \%)\end{array}$ \\
\hline 1 & $-.4837 *$ & .1055 & -.2602 & $.5609 *$ & .3639 & -.2087 & -.2039 \\
\hline 2 & -.1382 & .0271 & .0469 & $-.7014 *$ & -.2044 & -.3793 & -.1635 \\
\hline 3 & -.1125 & -.0396 & -.1142 & .0156 & $-.8628 *$ & .1531 & -.0335 \\
\hline 4 & -.1011 & -.0366 & -.0798 & .0318 & $-.6518 *$ & $-.5089 *$ & -.1385 \\
\hline 5 & $-.7899 *$ & .0089 & .1996 & -.0415 & -.1262 & .0366 & -.1687 \\
\hline 6 & $-.4851 *$ & $.7218^{*}$ & -.1013 & -.0432 & .1893 & .0114 & .0948 \\
\hline 7 & $-.9013 *$ & $.3946^{*}$ & .0992 & -.0024 & .0199 & -.0485 & -.0206 \\
\hline 8 & $-.9532 *$ & .1757 & .0125 & .0192 & -.1019 & -.0273 & .0358 \\
\hline 9 & $-.4544^{*}$ & -.3425 & -.0322 & .0106 & $.4242 *$ & -.0305 & $.6050 *$ \\
\hline 10 & .0702 & $-.5373^{*}$ & -.0568 & .0086 & $.4205^{*}$ & .0088 & $.6426^{*}$ \\
\hline 11 & $-.8056^{*}$ & $.5115^{*}$ & .1125 & -.0361 & .0252 & -.0837 & -.0012 \\
\hline 12 & $-.3951 *$ & $.7733^{*}$ & .1169 & .1463 & -.0255 & -.0279 & .0262 \\
\hline 13 & $-.9307 *$ & -.0881 & .1228 & .0561 & -.0550 & -.1288 & -.0583 \\
\hline 14 & -.2736 & $.4548 *$ & $.6778^{*}$ & -.1895 & -.1753 & .0693 & -.0290 \\
\hline 15 & $.7764 *$ & -.0073 & $.4312^{*}$ & -.1834 & -.1070 & .1802 & .0761 \\
\hline 16 & .0590 & .0015 & .1379 & .0460 & -.0773 & $.8301 *$ & .0049 \\
\hline 17 & -.1710 & $-.7178^{*}$ & -.1521 & .2131 & -.0053 & .0692 & .3152 \\
\hline 18 & -.1754 & .3378 & $.4396 *$ & .1075 & -.0200 & $-.7251 *$ & .1281 \\
\hline 19 & $-.7285 *$ & $.4809 *$ & -.3651 & -.0080 & -.1180 & -.0484 & .0005 \\
\hline 20 & .0068 & .3091 & $-.7633^{*}$ & -.0084 & -.2474 & -.0189 & .0042 \\
\hline 21 & -.1786 & $.7468^{*}$ & -.2597 & .0332 & .0194 & -.1202 & -.2056 \\
\hline
\end{tabular}

Note $-E V=$ explained variance. Parameters: $1=$ aggressive dominance index, $2=$ wins in runway test, $3=$ drinking time in water competition, $r=$ rank index (sums of rank positions in Parameters 1-3), $5=$ body weight at start, $6=$ body weight increase during experiment, $7=$ body weight at end, $8=$ heart weight (absolute), $9=$ thymus weight (absolute), $10=$ thymus weight (relative), $11=$ liver weight (absolute), $12=$ spleen weight (absolute), $13=$ kidneys weight (absolute), $14=$ adrenals weight (absolute), $15=$ adrenals weight (relative), $16=$ thickness of adrenal cortex, $17=$ nuclear count in adrenal cortex, $18=$ thickness of adrenal medulla, $19=$ testes weight (absolute), $10=$ testes weight (relative), $21=$ diameter of tubuli seminiferi. $\quad$ *Significant (>.381). 
lications used more than two independent parameters (Table 1). Competitive methods have been carried out in most experiments, because they are time-saving and relatively easy to carry out compared with investigations on spontaneous behavior. Apart from behavioral categories, we have, however, assessed two methodologically independent competition tests and at least 12 morphological parameters.

In agreement with other authors (Drews \& Dickey, 1977; Gage, 1978), we have included only a few major behavioral categories for the registration of spontaneous behavior during the first $10 \mathrm{~min}$ of the redlight phase, which appears as darkness to the rats (Calhoun, 1975). Aggressive rats, which were heavier and more agile and often the attack winners, induced multiple submissive positions on their cage partners (Table 2).

Other authors could also show the correlation between attack frequency, agility, and high body weight for rats in experimental and natural environments (Boice, 1972; Davis, 1979; Zook \& Adams, 1975). Attack behavior was frequently completed by induction of submission in the partner (Militzer \& Reinhard, 1979a; Silverman, 1978). Since the investigations by Grant and Chance (1958), this behavior has therefore been used for testing rank positions.

For young rats, the frequency of on-top position, which represents the induction of submission, has been the basis for dominance ranking of the pup within each litter (Meaney \& Stewart, 1981). Since attack wins and induction of submission are easily recognized and clearly interpretable, we have used their frequencies as suitable parameters of spontaneous antagonistic behavior (ADI, Tables 3 and 4).

In our experiment, boxing and anogenital control were correlated with each other but not with definite aggressive behavior. In agreement with other authors (Blanchard, Fukunaga, Blanchard, \& Keller, 1975; Lehman \& Adams, 1977; Silverman, 1965), boxing was thus assessed as an ambivalent behavioral category. Since it was also less clearly restricted to dominant animals, it did not represent a genuine attack strategy (Blanchard, Takahashi, \& Blanchard, 1977). Significant correlations have been shown to exist between boxing and fighting in Wistar rats (Drews \& Wulczyn, 1975; Spigel \& Fraser, 1974). Only in this rat strain could we confirm this result (Militzer \& Reinhard, 1979a). Due to unclear assessment criteria, it appeared to us that the behavioral category "boxing" was unsuitable for interpreting rank determining behavior in rats.

As with mice (Benton \& Brain, 1979), our experiments with rats also showed a correlation between frequent allogrooming and reduced attack behavior. Rats that are fearful groom particularly often (Cohen \& Price, 1979). Grooming was further observed as an afterreaction following irritating behavioral contact (Beagley, 1976; Bolles, 1960), as was appeasement following an intensive play-fight, in young rats
(Eibl-Eibesfeldt, 1958). Spigel and Fraser (1974) assumed it to be a "consummatory act" and recommended it as an indicator of social dominance. This form of grooming should be designated as aggressive (Silverman, 1978), although Lehman and Adams (1977) described it as explorative. Meaney and Stewart (1981) observed the so-called "neck grooming" as a form of play-fight in young rats. We support the differentiation in social and aggressive grooming, as recommended by Grant and Mackintosh (1963) and Timmermans (1978). The differentiation between both categories is only possible from a knowledge of the complete reaction chain. The numerical determination of a single behavioral gesture, as intended by us and most other authors, does not permit a clear interpretation for "grooming." Apart from spontaneous behavior, the outcome of competition tests was also registered. Our rats with many wins in the runway test crossed the alley slowly during training and frequently boxed during competition (Table 2). A correlation between training success and test results was also shown by Ward and Gerall (1968) in the same system. Runway-dominant rats showed frequent "freezing" (Spigel \& Fraser, 1974), that is, a motionless position as a result of a species-specific defense reaction (Timmermans, 1978) as a form of boxing.

The runway test allows a direct relationship to boxing and freezing to be made only because rats in these positions passively block the alley. Relevant conclusions as to rank positions are not to be expected from this experimental condition, since no positive correlations with spontaneous aggressive behavior and other competitive results exist.

With our rats, the water-competition method shows no correlation with a definite behavioral category. In other publications, however, the test results have been correlated with grooming (Drews \& Dickey, 1977; Spigel, Trivett, \& Fraser, 1972) as well as submission and boxing defeats (Drews \& Dickey, 1977). Timmermans (1978) questioned the relevance of these findings, since all tests were not carried out on the same day on real rat groups, as was the case in our experiment. Under these circumstances, our results clearly show that a unidimensional rank order within groups of male rats cannot be determined.

Correlations between unequivocal antagonistic behavioral categories and the competitive test results are missing both for the data of the overall test (Table 2) and for the last day (Table 3). In the factor analysis (Table 4), the rank parameters were distributed in different variable groups (Factor I, ADI; Factor IV, rank index). On the other hand, they were either oppositely orientated (Factor IV, ADI vs. wins in runway test) or methodologically dependent on one another (Factor V, drinking time and rank index). Other authors have also assigned the different parameters of rivalry in rats to various factors (Drews \& Dickey, 1977; Drews \& Wulczyn, 1975), or 
significant correlations were missing (Baenninger, 1970; Gärtner, Wankel, \& Gaudszuhn, 1981; Howells $\&$ Kise, 1974). We must thus assume that only relative rank orders for the various types of competition and rivalry in male rats exist (Bernstein, 1981; Tembrock, Note 1).

For the comparison between social rank positions and the morphological findings, it was therefore essential to judge each rank test result separately. From the unequivocal interpretation and the grouping within the factor with the highest amount of total variance (Table 4, Factor I), the determination of antagonistic behavior (ADI) in our experiments has shown itself to be superior to other rank criteria. Experiments obtained by animal psychologists under field conditions (Hendrichs \& Hendrichs, 1971; Lott, 1979) and the experimental data of Baenninger (1966) and Davis (1979), as well as Popova and Naumenko (1972), on rats, Noë, Waal, \& Hooff (1980) on chimpanzees in colonies, and Banks, Wood-Gush, Hughes, \& Mankovich (1979) on domestic fowl are thus confirmed: the determination of fighting and submission frequency represents a more suitable criterion of rank position than do complex artificial competition tests.

The ADI allows definite correlations to be made with the stress-dependent organs thymus, adrenals, and testes (Table 3). Furthermore, from the factor analysis, a similar, but negative, orientation of antagonistic rank (ADI) and body and organ weights, with the exception of the adrenals, was apparent (Table 4, Factor I). This indicated that few aggressive rats possess a reduced bodily condition with hyperplastic adrenals.

Boice (1972) noticed that subordinate rats from rubbish dumps are in bad shape and have lower rates of reproduction in captivity than do the healthy and uninjured high-ranking individuals. Vice versa, dominant Polynesian rats show high body weight, a good bodily constitution, and reproductive potential (Davis, 1979). Also, Barfield, Busch, and Wallen (1972) indicated that rats with a high androgen level showed a good sexual potential as well as exhibiting a distinct antagonistic behavior. High testes weight, wide tubuli seminiferi, and a narrow adrenal cortex with a high ADI was simultaneously shown in our rat collective (Tables 3 and 4).

Also, in our experiment, the negative correlation between rank and adrenal weight (Lloyd, 1975; Shire, 1974) becomes apparent when the relative weights are considered. Richardson and Keeling (1977) showed a reduced testes weight in stressed Sprague-Dawley rats; even in kangaroo rats, a short cold stress leads to a reduction in weight of the male sexual glands (Babero, Yousef, \& Wawerna, 1971). The above findings indicate a close association between social behavior and stress-dependent organ influences.

Stress appears not only to produce cortical hyperplasia (Benton \& Brain, 1979; Davis, 1979), but also to reduce the size of the adrenal medulla, as seen from the negative correlation of these parameters in our results. The size of the nuclei in the cortex, determined as the number of nuclei per defined area, is positively correlated to the cortical thickness but at the same time negatively to the absolute adrenal weight. We regard this nuclear edema as an indication of a stress-dependent ACTH effect, since Nussdorfer, Mazzocchi, and Rebonato (1971) have shown an increase of nuclear diameter morphometrically after hormone application.

Apart from the formation of gastrointestinal ulcers and adrenal hyperplasia, the regression of "thymicolymphatic tissue" is the one of the three objective symptoms of stress (Selye, 1973). Our results confirm that a decrease of thymus weight and an increase in adrenal weight occurs in rats with a low ADI (Table 3). The negative correlation between thymus and adrenal weight is also observed after sleep deprivation and cold water stress in Sprague-Dawley rats (Stern \& Hartmann, 1972), after rank fighting in voles (Clarke, 1953), and after induced illness in laboratory rats (Ivanova, Lapshina, \& Tsaplin, 1974).

In general, our morphological results confirm that the same unspecific reaction pattern of endocrine organs occurs independent of which social or physical stressing factors act on the animal ("general adaptation-syndrome" according to Selye).

\section{REFERENCE NOTE}

1. Tembrock, G. Personal communication, 1981.

\section{REFERENCES}

Aspey, W. P., \& Blankenship, J. E. Spiders and snails and statistical tales: Application of multivariate analyses to diverse ethological data. In B. A. Hazlett (Ed.), Quantitative methods in the study of animal behavior. New York: Academic Press, 1977.

Babero, B. B., Yousef, M. K., \& Wawerna, J. C. Histopathological changes in cold-exposed kangaroo rats, Dipodomys merriami. Comparative Biochemistry and Physiology, 1971, 39A, 361-366.

BaEnninger, L. P. The reliability of dominance orders in rats. Animal Behaviour, 1966, 14, 367-371.

BaEnninger, L. P. Social dominance orders in the rat: "Spontaneous," food, and water competition. Journal of Comparative and Physiological Psychology, 1970, 71, 202-209.

Balthazart, J. Validité de l'application de l'analyse factorielle a l'étude causale d'une séquence comportementale avec un essai d'analyse du comportement agonistique chez Tilapia macrochir (Boullenger, 1922). Annales de la Societe Royale Zoologique de Belgique, 1972, 102, 3-34.

Banks, E. M., Wood-Gush, D. G. M., Hughes, B. O., \& Mankovich, N. J. Social rank and priority of access to resources in domestic fowl. Behavioural Processes, 1979, 4, 197-209.

Barfield, R. J., Busch, D. E., \& Wallen, K. Gonadal influence on agonistic behavior in the male domestic rat. Hormones and Behavior, 1972, 3, 247-259.

Barnetr, S. A. Physiological effects of "social stress" in wild 
rats. I. The adrenal cortex. Journal of Psychosomatic Research, 1958, 3, 1-11.

BeAGLEY, W. K. Grooming in the rat as an aftereffect of lateral hypothalamic stimulation. Journal of Comparative and Physiological Psychology, 1976, 90, 790-798.

Benton, D., \& Brain, P. F. Behavioural comparisons of isolated, dominant and subordinate mice. Behavioural Processes, 1979, 4, 211-219.

Bernstein, I. S. Dominance: The baby and the bathwater. Behavioral and Brain Sciences, 1982, in press.

Blanchard, R. J., Fukunaga, K., Blanchard, D. C., \& Keller, M. J. Conspecific aggression in the laboratory rat. Journal of Comparative and Physiological Psychology, 1975, 89, 1204-1209.

Blanchard, R. J., Takahashi, L. K., \& Blanchard, D. C. The development of intruder attack in colonies of laboratory rats. Animal Learning \& Behavior, 1977, 5, 365-369.

BoICE, R. Some behavioral tests of domestication in Norway rats. Behaviour, 1972, 42, 198-231.

Bolles, R. C. Grooming behavior in the rat. Journal of Comparative and Physiological Psychology, 1960, 53, 306-310.

Boreman, J., \& Price, E. Social dominance in wild and domestic Norway rats (Rattus norvegicus). Animal Behaviour, 1972, 20, 534-542.

BrUCE, R. H. An experimental analysis of social factors affecting the performance of white rats. III. Dominance and cooperation motivated by water and food deprivation. Journal of Comparative and Physiological Psychology, 1941, 31, 395-412.

Calmoun, W. H. Quantification of behavior. In E. O. Price \& A. W. Stokes (Eds.), Animal behavior in laboratory and field. San Francisco: Freeman, 1975.

Candland, D. K., \& Bloomquist, D. W. Interspecies comparison of the reliability of dominance orders. Journal of Comparative and Physiological Psychology, 1965, 59, 135-137.

ChASE, J. D. Models of hierarchy formation in animal societies. Behavioral Science, 1974, 19, 374-384.

Clarke, J. R. The effect of fighting on the adrenals, thymus and spleen of the vole (Microtus agrestis). Journal of Endocrinology, 1953, 9, 114-126.

Cohen, J. A., \& Price, E. O. Grooming in the Norway rat: Displacement activity or "boundary shift"? Behavioral and Neural Biology, 1979, 26, 177-188.

Costanzo, D. J., Enloe, L. J., \& Hothersall, D. Effects of septal lesions on social dominance in rats. Behavioral Biology, 1977, 20, 454-462.

DAvis, L. S. Social rank behaviour in a captive colony of Polynesian rats (Rattus exulans). New Zealand Journal of Zoology, $1979,6,371-380$.

Drews, D. R., \& Dickey, C. L. Observational and competitive measures of dominance in rats. Psychological Record, 1977, 27, 331-338.

Drews, D. R., \& Wulczyn, F. H. Measuring dominance in rats. Psychological Record, 1975, 25, 573-581.

Eibl-EibesfeldT, I. Das Verhalten der Nagetiere 10. In W. Kükenthal \& T. Krumbach (Eds.), Handbuch der Zoologie. Berlin: De Gruyter, 1958.

Fukasawa, T., Lima, M. P., \& Masur, J. The behavior of genetically selected loser and winner-runway rats in different competitive situations. Behavioral Biology, 1975, 15, 333-342.

Gärtner, K., Wankel, B., \& Gaudszuhn, D. The hierarchy in copulatory competition and its correlation with paternity in grouped male laboratory rats. Zeitschrift für Tierpsychologie, 1981, 56, 243-254.

GAGE, F. H. A multivariate approach to the analysis of social dominance. Behavioral Biology, 1978, 23, 38-51.

Grant, E. C., \& Chance, M. R. A. Rank order in caged rats. Animal Behaviour, 1958, 6, 183-194.

Grant, E. C., \& Mackintosh, J. H. A comparison of the social postures of some common laboratory rodents. Behaviour, 1963, 21, 246-259.

Hendrichs, H., \& Hendrichs, U. Dikdik und Elefanten. München: Piper, 1971.
Howells, G. N., \& Kise, G. The measurement of social dominance in rats. Psychological Record, 1974, 24, 101-107.

HoyengA, K. T., \& Rowe, T. C. Assessing social dominance in pairs of male rats by measuring weight gain. Psychonomic Science, 1969, 16, 165.

HoYengA, K. T., \& LEKAN, R. K. The effect of rearing condition on dominance and emotionality in rats. Psychonomic Science, $1970,20,56$.

Ivanova, I. I., Lapshina, V. F., \& Tsaplin, V. M. Corticosterone content in the peripheral blood and adrenal glands during stress in rats with Alloxan diabetes. Problemy Endokrinologii (Moskva), 1974, 20, 94-97 (English abstract p. 97).

KREVELD, vaN D. A selective review of dominance-relations in animals. Genetic Psychology Monographs, 1970, 81, 143-173.

Lehman, M. N., \& AdAms, D. B. A statistical and motivational analysis of the social behaviors of the male laboratory rat. Behaviour, 1977, 61, 238-274.

LESTER, D. Exploratory behavior of dominant and submissive rats. Psychonomic Science, 1967, 9, 285-286.

LLOYD, J. A. Social behavior and hormones. In B. E. Eleftheriou \& R. L. Sprott (Eds.), Hormonal correlates of behavior. (Vol. 1): A lifespan view. New York: Plenum Press, 1975.

LoTT, D. F. Dominance relations and breeding rate in mature male American bison. Zeitschrift für Tierpsychologie, 1979, 49, 418-432.

Meaney, M. J., \& Stewart, J. A descriptive study of social development in the rat (Rattus norvegicus). Animal Behaviour, $1981,29,34-45$.

Mezei, T. C., \& Rosen, J. Dominance behavior as a function of infantile stimulation in the rat. Archives of General Psychiatry, 1960, 3, 77/53-80/56.

Micze K, K. A., \& BARRY, H. What does the tube test measure? Behavioral Biology, 1975, 13, 537-539.

Militzer, K., \& ReinhaRD, H.-J. Untersuchungen zur Rangordnung bei Laboratoriumsratten. 1. Ergebnisse von Beobachtungs- und Konkurrenztests. Zeitschrift für Säugetierkunde, 1979, 44, 256-278. (a)

Militzer, K., \& ReinhaRD, H.-J. Untersuchungen zur Rangordnung bei Laboratoriumsratten. 2. Vergleich von Rangpositionen mit pathologischen und morphometrischen Befunden. Zentralblatt für Veterinärmedizin (Reihe A), 1979, 26, 443-457. (b)

MonRoE, B. D. Influence of successful and unsuccessful social experiences on dominant-subordinate behavior in the rat. Developmental Psychology, 1970, 2, 359-363.

Nö̈, R., WaAl, de F. B. M., \& Hooff, van J. A. R. A. M. Types of dominance in a chimpanzee colony. Folia Primatologica, 1980, 34, 90-110.

Nussdorfer, G., Mazzocchi, G., \& Rebonato, L. Long-term trophic effect of ACTH on rat adrenocortical cells. An ultrastructural morphometric and autoradiographic study. Zeitschrift für Zellforschung, 1971, 115, 30-45.

OLDFIELD-Box, H. Individual performance in two experimental social organizations of rats. Animal Behaviour, 1969, 17, 534-536.

Popova, N. K., \& Naumenko, E. V. Dominance relations and the pituitary-adrenal system in rats. Animal Behaviour, 1972, 20, 108-111.

Price, E. O., Belanger, P. L., \& Duncan, R. A. Competitive dominance of wild and domestic Norway rats (Rattus norvegicus). Animal Behaviour, 1976, 24, 589-599.

Price, E. O., \& Huck, U. W. Open-field behavior of wild and domestic Norway rats. Animal Learning \& Behavior, 1976, 4, 125-130.

Richardson, J. H., \& KeEling, M. R. Comparison of accuracy in five measures of stress. Psychological Reports, 1977, 40, 980-982.

Ruskin, R. S., \& Corman, C. D. A multivariate study of competition in a free-operant situation. Psychonomic Science, 1971, 23, 251-252. (a)

Ruskin, R. S., \& Corman, C. D. The effects of varying levels of deprivation on the stability of dominance-submission hierarchies. Psychonomic Science, 1971, 23, 361-362. (b) 
Schjelderup-Ebbe, T. Soziale Verhältnisse bei Vögeln. Zeitschrift für Psychologie, 1922, 90, 106-107.

Schumsky, D. A., \& Jones, P. D. Reliable paired comparison dominance orders in rats. Psychological Record, 1966, 16, 473-478.

Selye, H. The evolution of the stress concept. American Scientist, 1973, 61, 692-699.

Shire, J. G. M. Review: Endocrine genetics of the adrenal gland. Journal of Endocrinology, 1974, 62, 173-207.

Silverman, A. P. Ethological and statistical analysis of drug effects on the social behaviour of laboratory rats. British Journal of Pharmacology, 1965, 24, 579-590.

Silve Rman, A. P. Animal behaviour in the laboratory. London: Chapman \& Hall, 1978.

Spigel, I. M., TrivetT, S., \& Fraser, D. Grooming behavior and competitive dominance in the albino rat. Journal of Comparative and Physiological Psychology, 1972, 78, 409-411.

SPIGEL, I. M., \& FRASER, D. "Dominance" in the laboratory rat: The emergence of grooming. Zeitschrift für Tierpsychologie, 1974, 34, 59-69.

Stern, W. C., \& Hartmann, E. L. Reduced amphetamine lethality following chronic stress. Psychopharmacology, 1972, 23, 167-170.
Syme, G. J. Competitive orders as measures of social dominance. Animal Behaviour, 1974, 22, 931-940.

Syme, G. J., Pollard, J. S., Syme, L. A., \& Reid, R. M. An analysis of limited access measure of social dominance in rats. Animal Behaviour, 1974, 22, 486-500.

TAYlOR, G. T., \& Moore, S. Social position and competition in laboratory rats. Journal of Comparative and Physiological Psychology, 1975, 88, 424-430.

Timmermans, P. J. A. Social behaviour in the rat. Doctoral dissertation, University of Nijmegen (The Netherlands), 1978.

Ward, I. L., \& Gerall, A. A. Dominance behavior in socially isolated rats. Psychonomic Science, 1968, 13, 39-40.

Wilson, E. O. Sociobiology. Harvard University Press, 1975.

Work, M. S., Grossen, N., \& Rogers, H. Role of habit and androgen level in food-seaking dominance among rats. Journal of Comparative Physiology, 1969, 69, 601-607.

Zook, J. M., \& Adams, D. B. Competitive fighting in the rat. Journal of Comparative and Physiological Psychology, 1975, 88, 418-423.

(Manuscript received February 20, 1980; revision accepted for publication February 1, 1982.) 